\title{
La colectividad judía en Melilla
}

\author{
León Levy
}

Es Melilla crisol donde se funden varias religiones representadas por sus respectivas colectividades: católica, musulmana, judía, hindú y algunos núcleos de tipo evangelista.

Es normativa inherente a nuestra ciudad la comprensión y respeto mutuos, dentro de la historia moderna no podemos señalar hechos motivados por fisuras dimanantes de la convivencia y que hayan creado enfrentamientos entre los diversos integrantes de tales colectividades. Prácticamente no existe labor de "apostolado" o captación de gentes, no es problema para nadie el conseguir conversiones. Tan sólo hace ya unos años se celebraron varias campañas misioneras y su objetivo eran los católicos más o menos observantes, pero no hubo intento ni proyecto de conseguir nuevos adeptos.

Sobre el origen de judios en Melilla no tenemos testimonios veraces. Podemos aludir al siglo VII donde aparece la figura legendaria de la Kahina o Bruja, que en mi opinión es la versión de Kohena (de la familia de Aaron el Sumo Sacerdote) que en el año 696 luchó contra los invasores de la ciudad.

Existiendo desde hace siglos judíos en Marruecos, independiente de los que llegaron expulsados de España, no era nada extraño habitaran la ciudad en los tiempos del Rey de Fez. Así la tradición oral nos habla de la existencia de una colectividad en 1492, precursora del abandono y destrucción de la ciudad. Tras la ocupación de la plaza por los españoles en 1497 y estando en vigor el Decreto de Expulsión es obvio considerar no existieran judíos.

Las informaciones más veraces y lejanas se remontan al año 1862 en que llega a Melilla acompañado de su esposa un judío argelino llamado Moisés Obadía, casado con Simi Abecasis, que procedía de Tetuán y, sin duda, por las tropas españolas de ocupación, tuvo noticias de nuestra ciudad. Ya en ella, intentó realizar comercio con las cábilas próximas pero halló dificultades y regresó a su tierra de nacimiento; descendientes suyos he tenido ocasión de conocer en Niza.

Varios años después, alrededor de 1864 vienen varios miembros de la familia Obadía, sin lazos de parentesco con el anterior, al parecer originarios de la cábila de Beni Sidel, pero propietarios de terrenos en la región del Zaio, quedando aún descendientes de éstos en nuestra ciudad.

De una forma un tanto esporádica van llegando algunos más, pero es tras la promulgación de la Constitución de 1869 , de tan gran espectro liberal y progresista, cuando la tolerancia de cultos queda permitida y se incrementa el número de judíos. La Guerra de 1893 (o de Margallo) trae algunos más.

Los sucesos de Taza, por el asalto a la ciudad por parte del Roghi Bu-Hamara, 
produce un éxodo de judios que se establecen en nuestra ciudad y las autoridades tienen que establecer un campamento para alojarlos. Existen actualmente numerosos descendientes de aquellos fugitivos. Más tarde, la Guerra de 1909, la Guerra Europea y por fin la Guerra de 1921, hacen incrementar notablemente el número de judios residentes en Melilla, que en 1936 llega a tener unas 6.000 almas, sin contar una población flotante que procedente de la zona sur de Marruecos, van y vienen en transaciones comerciales, como talaberteros, pequeños industriales ambulantes y otros menesteres.

Esta población está compuesta por venidos de Tetuán (los de mayor potencia económica) Debdou, Gibraltar, Argelia, Taza, Rif (especialmente de la Región de Achdir) y de las vecinas cábilas de Guelaia, Quebdana, Ulad Settut, Beni Sidel y otras. Asimismo de la parte ribereña del Rif (Cuatro Torres, Villa Jordana, etc.), aparte de un nutrido número de los ya nacidos en la propia ciudad.

Posteriormente una serie de circunstancias motiva una notable reducción en el censo a consecuencia de corrientes emigratorias, principalmente dirigida a Venezuela, Israel, Peninsula y Francia.

Los judíos de Melilla pertenecen al rito sefardi (español), recordemos que el judaismo está compuesto de dos grandes bloques: sefardim y askenazim (centroeuropeos). Al primero pertenece, además de los descendientes en sí de españoles expulsados, muchos otros que tienen el mismo tipo de liturgia, la prosodía en los rezos en lengua hebrea y otras costumbres. Los hay de Yemen, Siria, Egipto, etc.

Se debe consignar que prácticamente son todos de nacionalidad española, y sólo un reducidísimo cupo de franceses, ingleses, venezolanos y marroquíes (estos de avanzada edad).

Es de señalar la alta cota de moralidad que preside la existencia de la comunidad judia. Son observantes de una buena conducta pública y privada; no crean problemas a las autoridades. Son fieles cumplidores de las leyes, y prácticamente no se les conoce hechos delictivos.

A principios de la Guerra Civil de 1936 comenzó una propaganda antijudía y se les quiso poner el sambenito de usureros. Por parte de falangistas y autoridades se realizó una investigación y, de los 12 individuos a los que se achacaba practicar la usura, sólo había un judío y precisamente de la única familia identificada con Falange antes del Alzamiento.

Son buenos observantes de la religión, contando con instalaciones para el sacrificio de aves y ganado con arreglo a las prescripciones mosaicas. Existe el cementerio para el rito judio: las inhumaciones se realizan en tierra, no existen nichos ni tampoco exhumaciones para traslado a osarios o fosas comunes

La comunidad cuenta con un Colegio Hispano Israelita, en un hermoso edificio de tres plantas, donde se cursa enseñanza religiosa así como la E.G.B. El profesorado está compuesto por judios que imparten la religión y los del Magisterio Oficial para E.G.B. Este inmueble alberga asimismo la sede oficial de la comunidad, salón de actos, baños rituales, pequeño dispensario médico y otras instalaciones.

El Colegio llamado en principio "Talmud Torá" (Enseñanza de la Ley) también 
sufrió las consecuencias de la Guerra Civil y en principio fue incautado por las Milicias de Falange y posteriormente por el Mando Militar.

Las atenciones sociales y religiosas están cubiertas por la Junta Directiva de la Comunidad Israelita, Sección Femenina, Sociedad Benéfica de Jóvenes "Hozer Dalim" y una entidad llamada "Hebrá Guemilut Hasadim". Esta tiene a su cargo los auxilios espirituales a las personas en trance de muerte, atenciones post-mortem y enterramientos. Se compone de ramas masculina y femenina, todos voluntarios. Una serie de sinagogas, o templos, atienden las necesidades espirituales de la comunidad. En ellas se celebran oficios religiosos tres veces al día.

En el aspecto económico hay que destacar, que, pese a lo que piensan muchos, no hay grandes fortunas entre los judios melillenses. Hay que desterrar la leyenda de que todos los hebreros son ricos. Tanto en Melilla, como en el resto del Universo, hay más judios pobres que ricos.

El standard de vida es bueno, de un nivel medio. Hay numerosos pequeños comerciantes, la mayoria individuales, que, realmente, son obreros emancipados, lo que presta una estabilidad económica a la colectividad. Afortunadamente los indigentes son pocos y reciben ayuda, lo que evita tengan que acudir a la mendicidad. No hay un problema de paro acuciante, ya que gentes emprendedoras saben buscarse el sustento.

En Melilla la comunidad judía ha dado al traste con la vieja creencia de que todos los israelitas son comerciantes. En la juventud existe un deseo de capacitación, no existe el analfabetismo (a excepción de algunos ancianos). Un muy elevado porcentaje de ellos son al menos bachilleres y cuenta una elevada proporción de intelectuales: profesores de Universidad, Institutos, Escuelas Universitarias, E.G.B., médicos, licenciados en diferentes ramas (farmacia, química, geologia, psicología, matemáticas, económicas, comerciales, etc.), ingenieros, aparejadores y otras.

Dentro del plan cultural, pero remitidos a la facetä religiosa, hay que señalar que numerosos chicos, de posición económica muy débil, han recibido becas de entidades británicas, con las que cursaron estudios religiosos y actualmente contamos con melillenses que ejercen de rabinos en Reino Unido, Francia, Dinamarca, Guatemala, Venezuela, Singapoore, Hong Kong, Rhodesia y otros lugares.

El idioma usado en el seno de las familias judías de Melilla es el castellano. El hebreo sólo se usa en los rezos y es curioso observar ciertos actos litúrgicos en que se emplea el español. Incluso en las actas matrimoniales se alude al rito de las comunidades de Castilla. Además de los nombres propios bíblicos resulta interesante conocer nombres cotidianos usados por las judías tales como: Alegria, Fortuna, Preciada, Mercedes, Perla, Orovida, Estrella, Luna, etc.

A título anecdótico .eñalemos que hay un llamado Barrio Hebreo, donde en la antigüedad estuvo el Campamento de los refugiados de Taza, que ya hemos aludido, donde hará cerca de 60 años el filántropo judío melillense don Yamin Chocrón construyó una serie de viviendas de tipo social para los indigentes ·de la Colonia. Las calles llevan nombres tan alegóricos como Jerusalém, Sión, Tel Aviv, Jaifa, etc. Actualmente los habitantes judíos son minoría en el barrio que 
lleva su nombre.

La juderia melillense está plenamente integrada dentro de la población, no hay en la actualidad discriminaciones sensibles. Como ya hemos indicado la convivencia entre los melillenses de diferentes confesiones es buena.

En época pasada, nos referimos al 1936, a consecuencia de la Guerra Civil se plasmaron una serie de hechos de tipo discriminatorio. Este tema se elude de tratar, pero afortunadamente la derrota de la Alemania nazi implicó una caida de la corriente antisemita, no del todo desparecida pues se ha derivado en politica antiisraelí.

Es de mencionar que pese a que el judio melillense, es, en general, buen observante de la religión, no existe fanatismo y, menos, afán de proselitismo. Son abiertos a los demás y es fácil y frecuente asistir a actos religiosos tales como bodas, entierros y otros, por parte de los no judios. Asi, destaca especialmente una festividad de tipo fraterno que se celebra el último día de la Pascua del Pesah (llamada vulgarmente de la galleta) que es la de la conocida Noche de las Mesas. En todos los hogares judios se instalan mesas con dulces, bebidas, manjares, permaneciendo abiertas las puertas para recibir las visitas de conocidos, pudiendo verse a judios, católicos, musulmanes e hindúes.

Las festividades principales que celebra la colectividad judía son: Rosh Hashaná (Año Nuevo); Yom Kipur o Fiesta del Perdón, que comporta un severo ayuno de 27 horas; Sucot o Fiesta de los Tabernáculos, llamada vulgarmente de la Cabaña, porque se acostumbran hacer en los hogares o azoteas pequeñas cabañas en recuerdo de la estancia del pueblo judio en el Desierto de Sinai al salir del cautiverio en Egipto; Purim, celebra la suspensión de la matanza de judios acordada por el Rey Asuero gracias a la intervención de la Reina Esther; Hanucá, o de las luminarias, recordando la lucha heróica de los Macabeos, contra los romanos; Pesah, que implica el comer pan ácimo, recordando que los judios al salir de Egipto no pudieron preparar el pan leudo y se vieron obligados a comer el pan ácimo, sin levadura; Sabuoth, o Pentecostés, conmemorando la promulgación de la Ley mosaica.

Los niños al $80^{\circ}$ día reciben el bautismo judío por medio de la circuncisión o milá, que realiza el Mohel persona apta para ello. Las niñas tienen la imposición de nombre y por tanto su bautismo sin acto material alguno: una fiesta que en estas zonas se llaman las "fadas" recordando tiempos ancestrales en que se ponían las recién nacidas bajo la advocación de las hadas.

Al llegar los niños a los 13 años obtienen la mayoría de edad religiosa. Es decir, que se puede formar parte de los diez hombres que constituyen el "minian", necesario para dar fuerza legal a los actos religiosos en general (lo mismo litúrgicos, bodas, bautizos, etc.).

Este acto se realiza mediante la imposición de los tefilín, filacterias de cuero que se ponen en brazo izquierdo y cabeza durante los actos religiosos de la mañana (sahrit), excepto sábados y pascuas. Se le llama Bar Misvá.

En las mujeres, tras obtener una cierta preparación de sus deberes religiosos, se llega a la Bat Misvá. 
Razones de espacio impiden dar mayor extensión al tema, este trabajo va dedicado a los lectores de ALDABA, residentes fuera de Melilla, a fin de que tengan un somero conocimiento de los judios y sepan que son algo más que comerciantes o deicidas. 